\title{
"Estado-patrão": rumo ao desaparecimento do emprego público?
}

\section{Resumo}

O presente artigo focaliza as relações de trabalho praticadas pelas secretarias estaduais de educação junto aos docentes da educação básica em três níveis: macro, que abarca os contratos temporários firmados em cada estado e Distrito Federal; meso, o mesmo fenômeno é verificado no estado de São Paulo, um dos precursores no Brasil da lógica gerencialista orientada pela racionalidade econômica e pela política de resultados; e, micro, na Região Metropolitana de Campinas, com vistas a identificar a existência de algum padrão da precariedade praticado entre professores, segundo características socioeconômicas municipais, em especial a renda per capita, índices de vulnerabilidade social e de desenvolvimento humano. A pesquisa, de caráter documental, com base nos microdados do Censo Escolar e das estatísticas oriundas da Secretaria da Educação do Estado de São Paulo, permite afirmar que há um movimento crescente em todo o país, com raras exceções, pelo fim dos concursos públicos para professores da educação básica, ainda que essa seja a forma prevalente de contratação no país.

Palavra-chave: Trabalho docente; precariedade; relações de trabalho; política educacional.

\section{Selma Venco}

Universidade Estadual de Campinas

- UNICAMP - Campinas/SP - Brasil selma.venco@gmail.com

\section{Para citar este artigo:}

VENCO, Selma. "Estado-patrão": rumo ao desaparecimento do emprego público?. Revista Linhas.

Florianópolis, v. 22, n. 49, p. 82-105, maio/ago. 2021. 


\title{
The "Boss-State": towards the disappearance of public employment?
}

\begin{abstract}
This article focuses on the labor relations practiced by the state education secretariats with basic education teachers at three levels: macro, which covers temporary contracts signed in each state and the Federal District; meso, the same phenomenon is verified in the state of São Paulo, one of the precursors in Brazil of the managerialist logic guided by the economic rationality and the results policy; and, micro, in the Metropolitan Region of Campinas, in order to identify the existence of some standards of precariousness among teachers, according to the municipal per capita income, social vulnerability and human development indexes. The documental research, based on microdata from the School Census and statistics from the São Paulo State Department of Education, allows us to state that there is a growing movement across the country, with rare exceptions, due to the end of public tenders, although this is the prevalent form of hiring in the country.
\end{abstract}

Keyword: Teaching work; precariousness; work relationships; educational politics. 
A construção e a difusão da noção de um Estado oneroso e incapaz de enfrentar os altos custos provenientes do Estado do Bem-Estar-Social - mesmo considerando-se aqui a não efetivação no Brasil de tal política - e os desafios de uma sociedade globalizada, foram amplamente veiculados no Brasil desde o primeiro governo eleito democraticamente ${ }^{1}$ após vinte e um anos de ditadura civil-militar (1964-1985). É, no entanto, consolidada no governo Fernando Henrique Cardoso (FHC). Esse, adepto à Nova Gestão Pública (NGP) e alentado pela adesão à onda toyotista - que, entre outros aspectos, alavanca processos de flexibilização das relações de trabalho e consequente redução de acesso aos direitos vinculados ao trabalho -, adota medidas semelhantes no emprego do setor público.

A matriz política prevalente nos anos 1990, aderente à lógica empresarial, prega a necessidade da passagem do Estado burocrático para o gerencial, posto que uma administração pública moderna deveria abandonar a rigidez burocrática e estimular a participação das empresas privadas nas ações públicas (BRESSER-PEREIRA, 1998).

É nesse contexto que o presente artigo visa debater as formas de contratação dos docentes da educação básica por parte dos governos estaduais em três níveis: macro, em todos os estados do Brasil e Distrito Federal; meso, especificamente no estado de São Paulo; e, micro, na Região Metropolitana de Campinas, um dos maiores polos industriais do país, situada no estado de São Paulo, que congrega vinte municípios. Considera-se como hipótese que a racionalidade econômica - elemento central no Estado Gerencial estabelece metas anuais de contratos precários, com consequente desoneração da folha de pagamento, todavia sem considerar os efeitos à qualidade da educação decorrentes de tal política, nem tampouco as implicações deletérias às condições de vida desses profissionais.

A análise sustenta-se em pesquisa qualitativa, aqui considerada sua dimensão documental, cuja abrangência remete à sistematização e estudo dos dados estatísticos oficiais do Censo Escolar, de 2011 a 2020, realizado pelo Instituto Nacional de Estudos e Pesquisas Educacionais Anísio Teixeira (INEP); e com foco específico no estado de São

\footnotetext{
${ }^{1}$ Fernando Collor de Mello (1990-1992).
} 
Paulo com base nos dados fornecidos pela Secretaria da Educação do Estado de São Paulo.

Assim, o artigo apresenta, em primeiro lugar, considerações teóricas a respeito das relações de trabalho, bem como a construção conceitual em torno da precariedade, para, em seguida, passar à análise dos segmentos propostos.

\section{O conceito de precariedade nas relações de trabalho}

Ao iniciar o debate acerca da precariedade nas relações de trabalho, cumpre afirmar a matriz teórica na qual a presente análise se sustenta e que a distingue das condições de trabalho.

Compreende-se por relações de trabalho, com base na formulação de Delgado, ministro do Supremo Tribunal do Trabalho, as formas de contratação do trabalho e, assim, concernente a

[...] toda modalidade de contratação de trabalho humano modernamente admissível. A expressão relação de trabalho englobaria, desse modo, a relação de emprego, a relação de trabalho autônomo, a relação de trabalho eventual, de trabalho avulso e outras modalidades de pactuação de prestação de labor (como trabalho de estágio, etc.). Traduz, portanto, o gênero a que se acomodam todas as formas de pactuação de prestação de trabalho existentes no mundo jurídico atual. (DELGADO, 2007, p. 455)

Difere, portanto, do conceito de condições de trabalho, posto que essas são alusivas, conforme Gollac e Volkoff (2007), tanto ao caráter ambiental do local de trabalho, como iluminação, temperatura, ventilação, presença de substâncias tóxicas entre outros aspectos, quanto aquelas afiliadas à gestão do trabalho, evidenciadas pelas formas de pressão, pelo estabelecimento da cadência do trabalho e, pela adoção de estratégias que findam por se configurar como de assédio moral e, portanto, concebidas como agentes causadores de danos psicossociais, sobretudo em razão das recentes configurações da gestão do trabalho se apoiarem: "a pressão excessiva , a insegurança da 
carreira, falta de autonomia, isolamento, conflitos éticos... comprometem o bem estar e a integração social de muitos trabalhadores”2 (CINGOLANI, 2012, p. 114, tradução nossa).

É no bojo de um contexto histórico, político e econômico que emergem certos conceitos que os singularizam e ganham acepção e destaque especial. Considera-se aqui, que o conceito de precariedade se inscreve nessa lógica e ganha notoriedade nas análises no campo das ciências humanas, em especial na sociologia do trabalho e na economia nos anos 1970, cujos estudos são dedicados à elucidação de um fenômeno emergente no âmbito da reestruturação produtiva. Esta foi promotora da supressão de postos de trabalho devido à adesão política no uso das novas tecnologias e da guerra concorrencial em tempos de globalização, mas, igualmente, deu origem em alguns países e agudizou em outros a flexibilização das relações de trabalho e oportunizou a concretização de contratos de trabalho erigidos fora das normas legais, orientada pela lógica toyotista sintetizada na produção sob demanda e estoque zero, e na defesa da contratação arqueável de trabalhadores.

Os estudos franceses naquele período passaram a evidenciar um fenômeno de tipo novo no contexto dos países centrais, mas diferenciado na constituição histórica do mercado de trabalho no Brasil, com origens escravocratas e que já no século XIX consolida lei que conferia autonomia ao proprietário de terra para encerrar contratos (DEDECCA, 2005).

Para Jacques Magaud (1974), ocorre nesse contexto uma verdadeira cisão no mercado de trabalho e irá classificar os trabalhadores como "verdadeiros", aqueles amparados pela lei; e os "falsos" que tanto poderão conviver com o primeiro grupo no interior de uma mesma empresa, como serão alocados em uma empresa terceirizada. A teoria da segmentação não se confirma como tendência nos estudos franceses, em especial nos produzidos no campo da sociologia do trabalho, que problematiza o fenômeno de maneira a destacar a dinâmica presente nas formas de contratação na qual os trabalhadores com vínculos empregatícios portadores de direitos a eles vinculados poderiam, facilmente, passar a qualquer momento para outro, sem proteção. Linhart e Maruani (1982) enfatizam a existência de uma desestabilização dos empregos estáveis

\footnotetext{
2 Tradução livre. No original: "la pression excessive, l'insécurité de la carrière, le manque d'autonomie, l'isolement, les conflits éthiques...compromettent le bien-être et l'intégration sociale de beaucoup de travailleurs".
} 
expressa em dois movimentos simultâneos: de um lado, a expulsão direta e acentuada dos trabalhadores com garantias previstas legalmente, viabilizadas por demissões em massa, bem como a aplicação de outras estratégias como programas de demissão voluntária, antecipação da aposentadoria; e, de outro, a corrosão dos contornos do emprego protegido, com alterações nas negociações coletivas, redução das horas de trabalho, transferências para localidades mais distantes e de menor custo, entre outros aspectos.

A complexidade do tema remete à premência de análises aprofundadas sobre a condição salarial, sobre a qual Robert Castel (1998) trará importante contribuição ao destacar que a precariedade nas relações de trabalho conduz a um processo de precarização da vida posto estar, esse segmento, sujeito a trabalhos intermitentes, contratos por tempo determinado, tempo parcial, entre outros, cujo resultado será a inserção em uma população socialmente vulnerável. Cingolani (2005, p. 24, tradução nossa) coaduna com a perspectiva do referido autor, na medida em que, para ele "se o emprego precário pressupõe uma temporalidade produtiva distinta da temporalidade comum do trabalho, e se isso também expõe com mais frequência ao desemprego, refere-se também aos baixos rendimentos [...]"3.

Se a precariedade nas relações de trabalho acarreta consequências individualmente à classe trabalhadora, também o faz no plano coletivo. Para Robert Linhart (1978) e Beaud e Pialoux (1999), a precariedade esfacela os coletivos, tanto dividindo-os entre os detentores de direitos e os flutuantes no mercado de trabalho, como também a desfiliação, cujo sentido atribuído por Castel (1998) remete à eliminação da conexão à esfera do trabalho e às redes por ele propiciadas.

A junção de ambas as dimensões, individual e coletiva, resulta na perda de certa condição de vida e subsistência, mas igualmente rompe ou, ao menos, fragiliza os laços que os une à sociedade do trabalho. Acepção sustentada por Cingolani (2012) aponta que o vínculo empregatício precário rompe com a tradição vivenciada no taylorismo-fordismo e esvazia a construção da história coletiva.

\footnotetext{
3 Tradução livre. No original "Si l'emploi précaire suppose une temporalité productive qui sorte de la temporalité oridinaire du travail, et si celle-ci expose plus fréquement au chômage, il renvoie aussi à de faibles revenus $[\ldots] "$..
} 
No setor público, por sua vez, observa-se a rápida adesão à vaga precarizante das relações de trabalho. O "Estado-patrão" ou o Estado empregador, tal como denominado por Magaud (1974), alça a argumentação do necessário rompimento com a força enrijecedora do Estado Burocrático, cujas amarras seriam soltas pelo Estado Gerencial (BRESSER-PEREIRA, 1998), conforme passa-se a ser analisado.

Concebe-se a função pública como sendo aquela responsável por concretizar o direito à população e, portanto, cujo trabalho é dedicado ao interesse geral do país. A fundamentação, compreende-se, seria já legítima unicamente por esse aspecto e, assim, distante, por princípio, da produção da mais-valia. Para assumi-la, a Constituição Federal, em seu art. 37, aponta o ingresso ao setor público exclusivamente por concurso público, com exceções firmadas apenas para atendimento a situações de exceção e de caráter temporário (Inciso IX), bem como o art. 206 destaca que o ensino será ministrado mediante determinadas bases, entre elas, a valorização dos profissionais da educação, referente ao direito do acesso ao plano de carreira e ingresso exclusivo por concurso público de provas e títulos nas redes públicas.

O direito administrativo público prevê ser o agente público "uma espécie dentro do gênero servidores estatais, são os que possuem com a administração relação de trabalho de natureza profissional e não eventual"4 (MELLO, 2016, p. 248, grifo nosso). Assim, a flexibilização nas relações de trabalho pode ocorrer, segundo Di Pietro (2016), em situações puramente excepcionais, a exemplo da ocorrência de catástrofes naturais, eventos esportivos pontuais entre outros, mas sempre coerentes ao interesse público.

E, por essa razão, esses devem ter garantida a estabilidade no emprego, não por privilégio, mas para evitar a descontinuidade no serviço à população, conforme as alterações nos cargos máximos e intermediários do poder público. Desse modo, o concurso público e a estabilidade no cargo deveriam assegurar o devido distanciamento dos interesses particulares, colocando-se constantemente em favor da coletividade.

Além desse aspecto, aqui considerado de alta legitimidade, evoca-se outro com base em Castel (2009) que ressalta o papel social do Estado - condição sine qua non para

\footnotetext{
${ }^{4}$ Dado o caráter de descentralização da política, os estados da federação devem obedecer a Carta Magna e outras que regem, por exemplo, as formas de contratação, mas esses possuem autonomia para regular os planos de carreira, caracterização do agente público etc. Os agentes públicos que atuam no governo federal são regidos pela Lei n 8.112/90 e, por exemplo no estado de São Paulo, pela lei nº 10.261/68.
} 
o incremento da "interdependência social" - viabilizado pelos agentes públicos e que constrange a "dissociação social”. Essa se constitui na formulação central em defesa da seleção pública, distinta da praticada no setor privado, pois são os agentes públicos que conferem ininterrupção do acesso à população ao direito.

Pors e Aschieri (2015) dialogam com a perspectiva conceitual de Robert Castel (2009) e sintetizam que o Estado se equipara a um "amortecedor social" e interrompe processos de agudização das desigualdades sociais, com o intuito de viabilizar a criação de uma "sociedade de similares" (CASTEL, 2003, p. 34).

O candidato à primeira eleição direta à presidência do Brasil, após o período ditatorial, elege como palavra de ordem a "caça aos marajás", um ataque explícito aos funcionários públicos que, em sua concepção, recebiam altos salários e detinham muitos direitos para pouco trabalho e se constituíam como verdadeiros obstáculos para o crescimento econômico do país.

Seu sucessor, Itamar Franco (1992-1995), a despeito de ser mais moderado, dá continuidade ao projeto neoliberal e aprova a Lei n. 8.745, de 9 de dezembro de 1993, que ampliou o leque das formas de contração por excepcionalidade temporária de interesse público:

Art. $2^{\circ}$. Considera-se necessidade temporária de excepcional interesse público:

IV - admissão de professor substituto e professor visitante;

VII - admissão de professor, pesquisador e tecnólogo substitutos para suprir a falta de professor, pesquisador ou tecnólogo ocupante de cargo efetivo, decorrente de licença para exercer atividade empresarial relativa à inovação. (BRASIL, 1993, p. 1)

A recuperação histórica permite acompanhar a fertilização de um terreno para viabilizar a Reforma do Estado, iniciada no primeiro mandato do presidente Fernando Henrique Cardoso (1995-1998). Nesse período são construídas as bases legais para: o estabelecimento de parcerias público-privadas 5 , a privatização das empresas estatais, como também a flexibilização das relações de trabalho no setor público. Apoiado nessa

\footnotetext{
${ }^{5}$ Instituída pela Lei n 9.790, de 23 de março de 1999.
} 
tríade, o governo federal chancelou o mercado e o alavancou a uma posição central na execução das políticas públicas.

No que tange às formas de contratação no setor público, o Decreto $\mathrm{n}^{\circ} 2271$, de 7 de julho de 1997, prevê:

Aquilo que represente atividade com similaridade no setor privado deve ser objeto de execução indireta, mediante contratação de prestadores de serviço, nas condições que permitam a maior economia de custos. (BRASIL, 1998, p. 46)

Para Magaud (1974), o Estado segmenta seu próprio mercado de trabalho e age de forma a lhe conferir maior liberdade para contratar e demitir trabalhadores que, de fato, exercerão as mesmas funções dos concursados, com vistas a obter importante redução de custos na folha de pagamento, pois os contratados hors norme não contarão com o conjunto de direitos previstos aos estatutários.

Tomam-se, assim, como objeto de análise, as relações de trabalho praticadas no setor público, mais especificamente, aquelas referentes à contratação de professores da educação básica nas redes estaduais de todo o país e, como informado, no estado de São Paulo e RMC.

\section{Macro: o Brasil rumo ao desaparecimento do emprego público?}

É possível afirmar que a seleção pública para professores da educação básica nas redes estaduais em todo o país é ainda a forma prevalente, pois seis em cada dez professores são concursados. Não obstante, é relevante constatar que $40 \%$ vivenciam contratos temporários, sobretudo porque há nítido movimento crescente entre 2011 e 2018, pois salta de 31 para 40\%, com curva ascendente especialmente a partir de 2015, como demonstrado no Gráfico 1. 
Gráfico 1 - Distribuição de docentes não concursados, nas redes estaduais do Brasil e Distrito Federal: $2011-2020$ (\%)

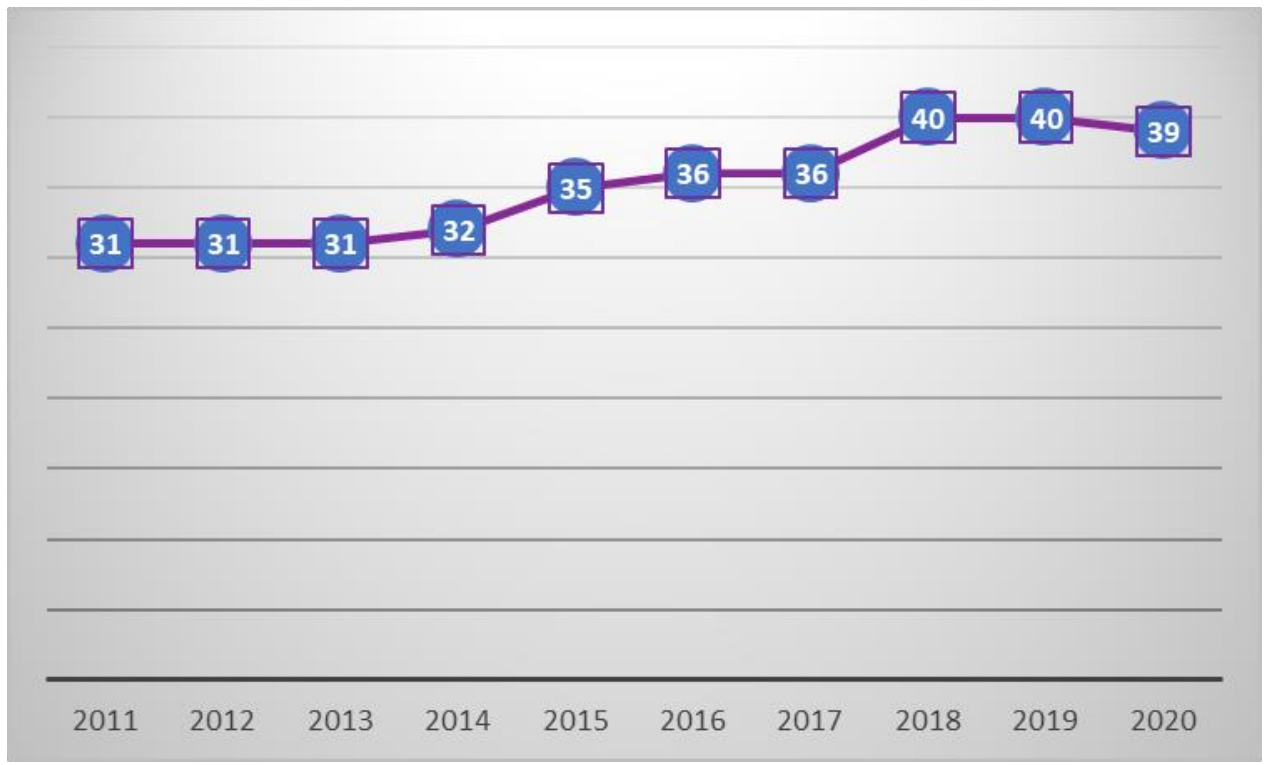

Fonte: MEC/INEP/Censo Escolar, 2011 - 2020. Elaboração própria.

Pressupõe-se, ensejando pesquisas mais detalhadas sobre os estados, que há uma adesão generalizada à nova gestão pública orientada pela contenção de recursos, via a não realização de concursos públicos, cujos cortes recaem, portanto, sobre os docentes.

Aponta-se como aspecto importante e inquietante o fato de somente Amazonas, Rondônia, Rio Grande do Norte e Sergipe terem estabelecido políticas voltadas à redução de professores temporários no conjunto de 26 estados e Distrito Federal. A despeito da presença de tal movimento, destaca-se que o estado do Amazonas ainda conta com 1/3, em 2019, dos professores em contratação precária, mas recua para 13\% em 2020 (Tabela 1). 
Tabela 1 - Distribuição de docentes da educação básica não concursados, nas redes estaduais - movimento decrescente, 2011-2020 (\%)

\begin{tabular}{|l|c|c|c|c|c|c|c|c|c|c|}
\hline \multicolumn{1}{|c|}{ UF } & 2011 & 2012 & 2013 & 2014 & 2015 & 2016 & 2017 & 2018 & 2019 & 2020 \\
\hline Rondônia & 26 & 20 & 20 & 16 & 15 & 10 & 8 & 11 & 16 & 18 \\
\hline Amazonas & 46 & 44 & 38 & 36 & 38 & 21 & 25 & 29 & 30 & 13 \\
\hline $\begin{array}{l}\text { Rio } \\
\text { Grande } \\
\text { do Norte }\end{array}$ & 22 & 16 & 5 & 11 & 10 & 3 & 3 & 6 & 7 & 5 \\
\hline Sergipe & 32 & 40 & 6 & 1 & 2 & 2 & 3 & 7 & 8 & 10 \\
\hline
\end{tabular}

Fonte: MEC/INEP/Censo Escolar, 2011 - 2018. Elaboração própria.

Na situação oposta a essa dinâmica, outros oito estados apresentam entre si média, em 2020, de praticamente seis professores com contratos precários em cada dez, ao longo da série histórica. Os principais destaques referem-se aos estados do Acre, Mato Grosso do Sul e Espírito Santo cujos percentuais são mais elevados. No estado do Acre, em 2011, mais da metade do total de docentes não eram concursados (54\%), mas gradativamente logra 81\%, em 2019, e, em 2020, reduz para 74\%; o Espírito Santo, por sua vez, trilha lógica semelhante e tinha 60\% de professores não efetivos em 2011, e amplia ainda mais a contratação temporária chegando em 76\%, em 2018 e encerra a série histórica com alguma redução (64\%).

A justificativa possível para o estabelecimento dessa política poderia estar vinculada aos estados com baixa arrecadação de impostos ${ }^{6}$. Porém, tal premissa não se verifica, pois, Minas Gerais e Santa Catarina, adotaram massivamente tal política, pois contabilizaram 68 e 73\%, respectivamente, de professores não concursados, em 2018; e 60 e $54 \%$ em 2020.

Há em Minas Gerais uma particularidade: a quantidade de docentes precários foi drasticamente reduzida em 2014, chegando a 19\%. Aécio Neves (PSDB) quando à frente do governo entre 2003 e 2010, em dois mandatos, promulgou a Lei 100, conhecida como a Lei dos Designados, cujo propósito foi transformar 98 mil docentes - que, à época, não 6 Segundo dados da Receita Federal disponibilizados no site <https://receita.economia.gov.br/dados/receitadata/arrecadacao/arrecadacao-por-estado/arrecadacao-uf2019> Acesso em: 01 jul. 2020. 
contavam, inclusive, com direitos previstos na CLT - em funcionários públicos sem submissão a concurso público. Em março de 2014, o Supremo Tribunal Federal declarou inconstitucional a lei e, por essa razão, o número de docentes não efetivos alcança o percentual de $57 \%$ em 2015, sendo ampliado ano a ano até atingir o percentual de $69 \%$ em 2019, com recuo para 54\% em 2020, conforme Tabela 2.

Tabela 2 - Distribuição de docentes da educação básica não concursados, nas redes estaduais - movimento ascendente, 2011-2020 (\%)

\begin{tabular}{|l|c|c|c|c|c|c|c|c|c|c|}
\hline \multicolumn{1}{|c|}{ UF } & $\mathbf{2 0 1 1}$ & $\mathbf{2 0 1 2}$ & $\mathbf{2 0 1 3}$ & $\mathbf{2 0 1 4}$ & $\mathbf{2 0 1 5}$ & $\mathbf{2 0 1 6}$ & $\mathbf{2 0 1 7}$ & $\mathbf{2 0 1 8}$ & $\mathbf{2 0 1 9}$ & $\mathbf{2 0 2 0}$ \\
\hline $\begin{array}{l}\text { Santa } \\
\text { Catarina }\end{array}$ & 50 & 59 & 56 & 53 & 53 & 56 & 60 & 73 & 62 & 60 \\
\hline $\begin{array}{l}\text { Mato } \\
\text { Grosso } \\
\text { do Sul }\end{array}$ & 58 & 59 & 61 & 61 & 61 & 62 & 65 & 71 & 68 & 65 \\
\hline $\begin{array}{l}\text { Mato } \\
\text { Grosso }\end{array}$ & 68 & 65 & 64 & 66 & 37 & 62 & 65 & 64 & 64 & 51 \\
\hline $\begin{array}{l}\text { Espírito } \\
\text { Santo }\end{array}$ & 60 & 68 & 71 & 74 & 73 & 46 & 59 & 76 & 62 & 64 \\
\hline \begin{tabular}{l} 
Paraíba \\
\hline
\end{tabular} & 55 & 52 & 44 & 47 & 29 & 30 & 28 & 52 & 52 & 48 \\
\hline Ceará & 60 & 63 & 69 & 72 & 61 & 57 & 60 & 61 & 63 & 65 \\
\hline Acre & 54 & 63 & 65 & 58 & 62 & 78 & 72 & 78 & 81 & 74 \\
\hline $\begin{array}{l}\text { Minas } \\
\text { Gerais }\end{array}$ & 28 & 20 & 12 & 19 & 57 & 65 & 65 & 68 & 69 & 54 \\
\hline
\end{tabular}

Fonte: MEC/INEP/Censo Escolar, 2011 - 2020. Elaboração própria.

A despeito de estados como Amapá, Maranhão, Rondônia, Bahia, São Paulo e Rio Grande do Sul apresentarem margens estáveis de contratação precária ao longo da série histórica, isso não significa que seus percentuais sejam pouco significativos. Maranhão e Rio Grande do Sul alcançaram percentuais de 39\% em 2018, mas passam para 45\% em 2020.

O estado do Rio de Janeiro é a exceção no conjunto dos estados, uma vez que apresenta percentuais variáveis entre 2 e 1\%. Uma explicação possível a ser investigada com maior profundidade é a redução da ordem de $45 \%$ de matrículas na rede estadual no período de 2007 a 2019 (INEP, 2007 a 2019) e expressivo crescimento do setor privado, 
dados que podem explicar uma parte do problema, mas evidenciam outro, que é a redução da participação do Estado no direito à educação.

Os destaques para o estado de São Paulo, maior e mais rico estado da Federação, são tratados no item que segue.

\section{Meso: o estado de São Paulo}

A pesquisa documental concernente ao conjunto das legislações aprovadas pelo governo do estado de São Paulo demonstra que a contratação de docentes sem concurso público não é, de fato, recente. Em $1887^{7}$, os professores eram nomeados, mas cabia algum tipo de contratação aos não aprovados em concurso público. Os marcos legais referentes a esse objeto vão sendo gradativamente modificados, de forma a contemplar um grau crescente de flexibilidade nas relações de trabalho, sendo aceitos, a partir de $1989^{8}$, estudantes universitários cursando o último ano; mas aceitando, dez anos depois, graduandos que tivessem cursado ao menos um semestre ${ }^{9}$. A despeito da Portaria indicar que esses ministrariam aulas da licenciatura em andamento, de fato, os contratados em caráter temporário assumiam aulas de qualquer disciplina, exceto educação física ${ }^{10}$.

Contudo, ressalta-se que as modificações sofridas ao longo de sua história transcendem a condição de exceção e passam, paulatinamente, a ser elemento constitutivo de uma gestão marcada pela racionalidade econômica, especialmente a partir de 1995.

Nesse cenário, nos anos 1990, já são apreendidos os reflexos nas relações de trabalho orientados por tal opção política, pois no período de $1996^{11}$ a 2005, tomando novembro como mês de referência, os professores não efetivos superavam os concursados, como demonstrado no gráfico 2.

\footnotetext{
7 Lei $n^{\circ} 811$, de 2 de abril de 1887.

${ }^{8}$ Portaria DRHU n ${ }^{\circ} 6$, de 15 de setembro de 1989.

9 Portaria DRHU n 12/1999.

${ }^{10}$ Sobre isso, ver: MATTOS, 2012.

${ }^{11}$ É importante informar que a opção por iniciar a série histórica em 1994 se deve ao fato de a Secretaria da Educação do Estado de São Paulo fornecer dados a partir dessa data.
} 
Gráfico 2. Distribuição dos professores, Educação Básica, Secretaria da Educação do Estado de São Paulo (PEBs I e II*), 1994-2018 (nº abs.)

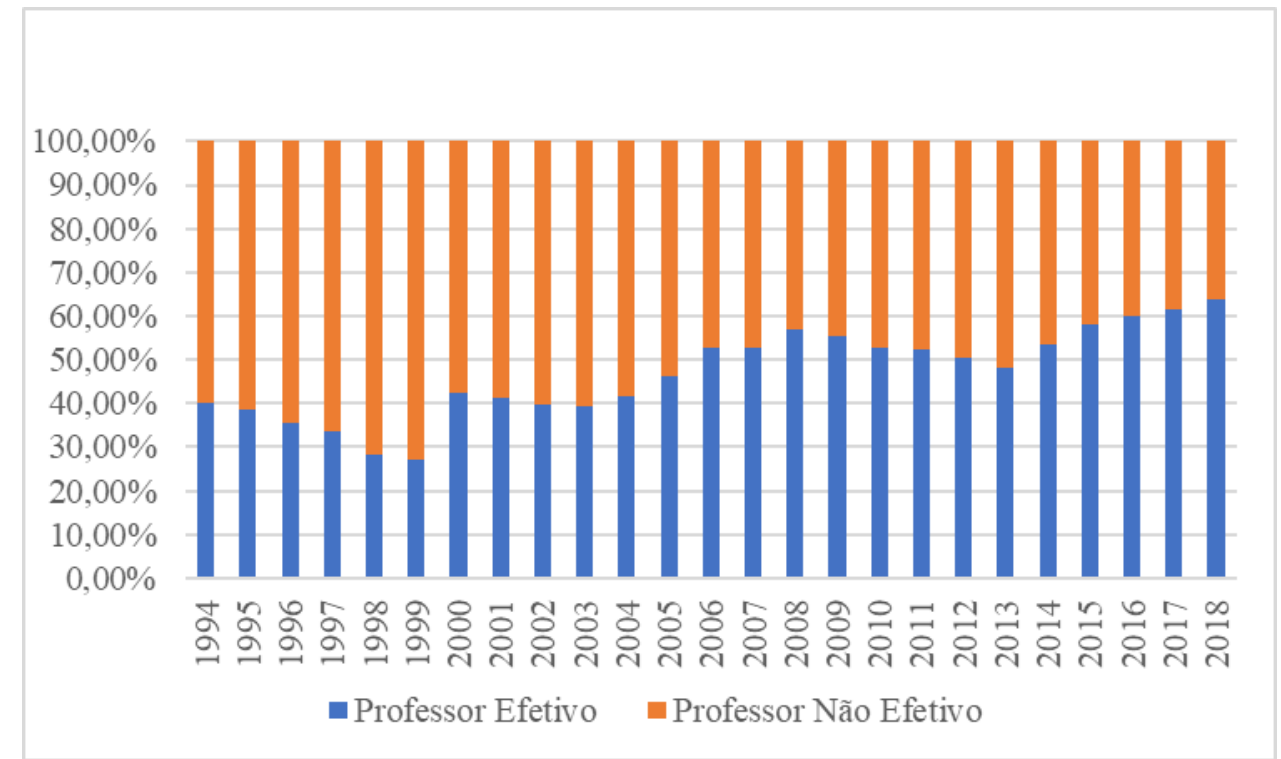

Fonte: BARBOSA, A. et al (no prelo) SEDUC-SP, 1999 a 2018.

PEB I - professor de educação básica Ensino Fundamental I

PEB II - professor de educação básica Ensinos Fundamental II e Médio

A partir de 2005 observa-se um movimento descendente, mas, ainda assim, com oscilação dos não efetivos entre 40 e 50\% até 2016, quando é iniciado um processo de retração. Entretanto, é importante problematizar os dados à luz de outras medidas adotadas concomitantemente no período, com vistas a não os compreender como uma política de elevação da seleção pública, via concurso.

Desde 2016, a Secretaria passou a determinar o fechamento de salas com número de estudantes inferior à sua capacidade (SEDUC-SP, 2016), mas superlotando as demais. A medida expressa a tendência marcada pela racionalidade econômica no governo paulista, uma vez que a redução de número de alunos por turma poderia resultar em melhores processos de ensino-aprendizagem e de condições de trabalho.

Houve, além disso, efetiva restrição de contratos temporários entre 2017 e 2019. Nesse período, as Diretorias Regionais eram informadas por e-mail sobre o número máximo de contratos que, de fato, estavam distantes de suprir a real demanda para preenchimento dos postos de trabalho. É, portanto, factível presumir que com tais medidas sobejaram aulas não atribuídas e uma quantidade desconhecida de estudantes permaneceram sem professor em determinadas disciplinas por tempo indeterminado. 
Em 2020, considerando o cenário da pandemia, o Decreto $n^{\circ}$ 64.937, em 12 de abril do mesmo ano, dispõe sobre a redução de despesas e encargos com pessoal, cuja tradução será feita à rede via Boletim de Instruções acerca dos procedimentos para aulas sem professor, posto ser coibido o estabelecimento de novos contratos:

Outros docentes da mesma disciplina ou da mesma área irão postar as atividades para a turma sem professor, e receberão como eventual, desde que o horário da turma sem docente não coincida com o seu horário de aula. Na ausência de docentes para atribuição regular ou para postagem de atividades (atuação eventual), as turmas de alunos serão acompanhadas nas aulas do Centro de Mídias pelo PMEC, Professor da Sala de Leitura, Professor Articulador, PC ou VDE, conforme o previsto na Resolução Seduc 01/2019. (SEDUC, 2020, p. 6)

Mesmo em situações de licença saúde, gestante ou licença-prêmio foram suspensas as possibilidades de substituição, exceto pelos concursados. E, assim, os arranjos - já tradicionais na educação sob a responsabilidade do governo paulista - se aprofundam e contradizem o discurso pela melhoria da qualidade da educação.

Finalizando o item meso, referente ao estado de São Paulo, é importante, ainda, apresentar as encruzilhadas analíticas enfrentadas nos estudos concernentes às relações de trabalho dos professores.

O cotejamento dos dados na série histórica com fontes oficiais e distintas, quais sejam: estado de São Paulo e Censo Escolar revela que as disparidades são vultosas. Isso porque, pelo INEP, a precariedade média entre professores da rede estadual, entre 2011 e 2018 , coletada em maio, é de $21 \%$, mas segundo o governo paulista é de $44 \%$ em novembro e $40 \%$ em janeiro (Tabela 3 ). 
Tabela 3 - Distribuição professores não efetivos, rede estadual paulista, SEDUC e INEP - 2011 a 2018 (em \%)

\begin{tabular}{|l|c|c|c|}
\hline & \multicolumn{2}{|c|}{ SEDUC-SP } & Censo/INEP \\
\hline Ano & Janeiro & Novembro & Maio \\
\hline $\mathbf{2 0 1 1}$ & 47 & 48 & 18 \\
\hline $\mathbf{2 0 1 2}$ & 40 & 49 & 23 \\
\hline $\mathbf{2 0 1 3}$ & 45 & 52 & 24 \\
\hline $\mathbf{2 0 1 4}$ & 39 & 45 & 25 \\
\hline $\mathbf{2 0 1 5}$ & 39 & 42 & 14 \\
\hline $\mathbf{2 0 1 6}$ & 41 & 40 & 15 \\
\hline $\mathbf{2 0 1 7}$ & 38 & 40 & 11 \\
\hline $\mathbf{2 0 1 8}$ & 29 & 36 & 18 \\
\hline Média & 40 & 44 & 25 \\
\hline
\end{tabular}

Fonte: SEDUC, INEP, 2011-2018. Elaboração própria, 2021.

Pondera-se que a despeito das diferenciações metodológicas, e mesmo havendo meses díspares de referência em ambas as fontes, ainda assim é de difícil explicação a diferenciação expressiva entre os governos federal e estadual. Nesse sentido, ajuíza-se que os dados da Secretaria de Estado originam-se da folha de pagamento e, portanto, mais fidedignos, enquanto o censo educacional preenchido, feito pelas escolas, com potencial falta de funcionários e intensificação do trabalho do diretor (MATTOS, 2020), podem comprometer tais dados e, consequentemente, um sem número de análises igualmente distorcidas.

\section{Micro: a Região Metropolitana de Campinas}

Como visto, a adoção da política de redução de custos gerou percentuais importantes de precariedade nas relações de trabalho praticadas pelo governo paulista junto aos professores. A análise da presença de contratos temporários por escola revela que a maior parte das unidades escolares contam entre 30,1 e 60\% de professores não concursados desde 2011, conforme demonstrado no gráfico 4 . 
Gráfico 4 - Distribuição de escolas, segundo intervalos percentuais de contratos precários, professores educação básica, 2011-2018 - rede estadual paulista ( $n^{\circ}$ abs)

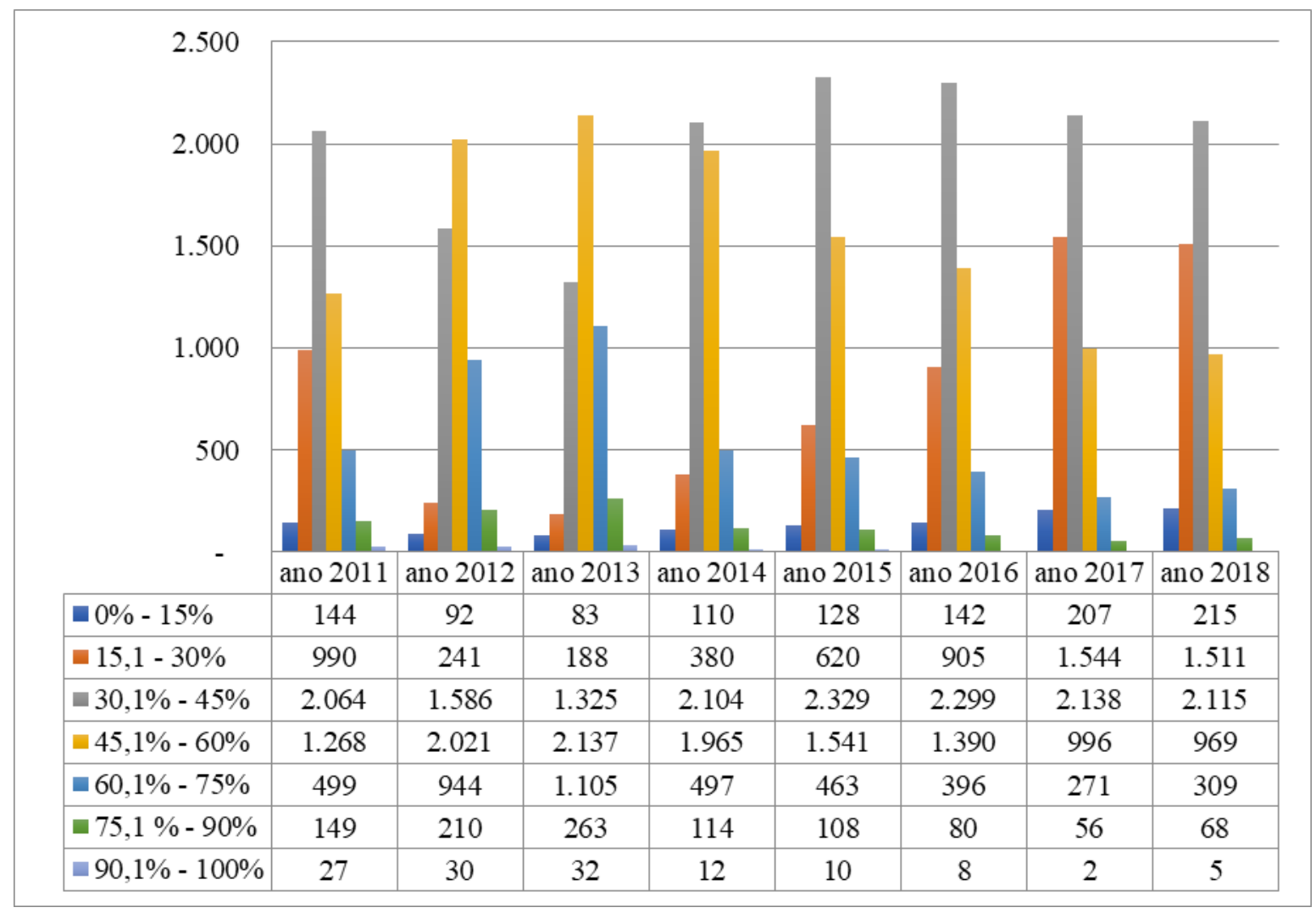

Fonte: Seduc-SP (2011 a 2018). Elaboração própria, 2021.

O recorte micro, ora proposto, investiga as ocorrências do mesmo fenômeno na Região Metropolitana de Campinas (RMC), composta por vinte municípios com características socioeconômicas significativamente heterogêneas. Quatro deles, congregam rendimentos mais substantivos: Campinas, Holambra, Valinhos e Vinhedo; enquanto outros apresentam renda média em torno de meio salário mínimo, a exemplo de Engenheiro Coelho, Hortolândia, Monte Mor e Santo Antônio de Posse. A RMC representa $8,3 \%$ do PIB paulista e $2,7 \%$ do PIB Nacional (SEADE, IBGE, 2010) e conta com importante parque industrial, destacadamente pela presença de empresas como a Petrobrás, em Paulínia e Ambev, em Jaguariúna, as quais contribuem sensivelmente para a elevação do Produto Interno Bruto, mas não refletem efetivamente em distribuição de renda ao conjunto da população.

A Região conta, segundo dados fornecidos pela SEDUC-SP, com 266 escolas e, em 
termos de precariedade das relações de trabalho entre professores da rede estadual, acompanha a média estadual: em 2019, registrou média de 35\%. Alguns municípios como Artur Nogueira, Monte Mor, Morungaba, Nova Odessa, Paulínia, Pedreira e Santa Bárbara D’Oeste superaram a média e apresentaram percentuais compreendidos entre 35 e 40\%; e, Americana, Campinas, Engenheiro Coelho, Hortolândia e Sumaré tiveram média igual ou superior a $41 \%$.

Não obstante, há escolas com percentuais elevados de contratos precários em 2019, como: a Escola Estadual Prof. Paulo Luiz Decourt, que funciona $100 \%$ com professores não efetivos; a escola Jardim Aline, em Hortolândia, com 94\% dos professores nessa condição ou a Profa Zoraide Proença Kaysel, com 82\%, em Sumaré.

Observa-se com base na tabela 4, que a RMC acompanha o movimento mais geral do estado de São Paulo e concentra seus percentuais de precariedade principalmente entre 30,1 e 45\%; e, tanto em 2011 como em 2019 pode-se afirmar que 4 em cada 10 escolas da referida Região estavam nessa situação.

Tabela 4 - Distribuição das escolas estaduais paulistas da Região Metropolitana de Campinas, segundo percentual de docentes não efetivos da educação básica ( $n^{\circ}$ abs) $2011-2019$

\begin{tabular}{|l|c|c|}
\hline$\%$ & $\mathbf{2 0 1 1}$ & $\mathbf{2 0 1 9}$ \\
\hline 0 a 15 & 9 & 15 \\
\hline $\mathbf{1 5 , 1}$ a 30 & 58 & 74 \\
\hline 30,1 a 45 & 109 & 105 \\
\hline 45,1 a 60 & 70 & 44 \\
\hline 60,1 a 75 & 19 & 25 \\
\hline 75,1 a 90 & 0 & 2 \\
\hline 90,1 a 100 & 1 & 1 \\
\hline
\end{tabular}

Fonte: Seduc-SP. Elaboração própria, 2021.

Buscou-se compreender a possível relação entre a caracterização do município, considerando a renda per capita municipal, o Índice de Vulnerabilidade Social (IVS) ${ }^{12}$, o

\footnotetext{
12 O IVS resulta da combinação de três dados municipais: fluxo de renda, condições de moradia e acesso à educação. O índice varia de 0 a 1, sendo que quanto mais próximo a 1, maior será a vulnerabilidade social do município.
} 
Índice de Desenvolvimento Humano $(\mathrm{IDH})^{13}$ e os percentuais de precariedade nas relações de trabalho dos docentes das escolas estaduais. Entre os que possuem maior renda, a média, em 2019, foi de 36\%, enquanto para os de menor renda há um acréscimo de sete pontos percentuais, resultando em uma média de mais de 4 professores não efetivos em cada 10. Valinhos, o município com maior renda per capita ( $R \$ 1.570,91)$ conta com 30\% de professores temporários, enquanto Sumaré ou Engenheiro Coelho, dois entre os menores rendimentos, cada um tem praticamente metade (47\%) dos professores não efetivos (Tabela 5).

Tabela 5 - Distribuição do percentual de docentes não efetivos da educação básica nas escolas estaduais paulistas nos municípios da RMC (2019), renda per capita (2017), índices de vulnerabilidade social e de desenvolvimento humano (2010)

\begin{tabular}{|l|c|c|c|c|}
\hline Municípios & $\begin{array}{c}\text { \% não } \\
\text { efetivos } \\
2019\end{array}$ & Renda (R\$) & IVS & IDHM \\
\hline Valinhos & 30 & $1.570,91$ & 0,179 & 0,819 \\
\hline Vinhedo & 33 & $1.493,32$ & 0,175 & 0,817 \\
\hline Campinas & 41 & $1.390,83$ & 0,277 & 0,805 \\
\hline Holambra* & 32 & $1.274,53$ & 0,117 & 0,793 \\
\hline Americana & 42 & $1.161,68$ & 0,149 & 0,811 \\
\hline Média & 36 & $1.378,25$ & & 0,762 \\
\hline Sumaré & 47 & 820,03 & 0,244 & 0,715 \\
\hline Morungaba * & 40 & 733,72 & S/I & 0,732 \\
\hline Eng. Coelho* & 47 & 707,37 & 0,284 & 0,756 \\
\hline Hortolândia & 44 & 686,96 & 0,308 & 0,733 \\
\hline Monte mor & 38 & 674,23 & 0,326 & $0,792(\mathrm{RMC})$ \\
\hline Média & 43 & 724,462 & $0,248(\mathrm{RMC})$ & \\
\hline
\end{tabular}

Fonte: Seduc-SP; IBGE, 2010, 2017. Elaboração própria. S/I - Sem informação, 2021.

\footnotetext{
${ }^{13} \mathrm{O}$ IDH considera, igualmente, três dados municipais: longevidade, educação e renda. O índice varia de 0 a 1, cuja leitura significa dizer que quanto mais próximo ao 1 estiver o município, maior o desenvolvimento humano do município.
} 
A observância da articulação entre os critérios elencados expressos pela renda per capita e os índices de vulnerabilidade social e desenvolvimento humano revela nexos com a precariedade entre professores, e demandam estudos locais com maior profundidade. No entanto, é relevante destacar que os municípios com percentuais mais elevados de contratos temporários são também os com os piores índices e rendimento.

A Secretaria do Estado de São Paulo, desde 1991, remunera os profissionais professores e funcionários - que atuam em áreas consideradas de risco ${ }^{14}$, mas somente em municípios com população acima de 300.000 habitantes e, portanto, na RMC apenas Campinas e Americana possuem escolas nessa condição.

\section{Considerações finais}

O artigo visou debater a incidência de contratos precários entre docentes da educação básica nas redes estaduais em três níveis: nos governos estaduais e Distrito Federal, no estado de São Paulo e os que atuam na Região Metropolitana de Campinas, mais especificamente o de docentes.

Apreende-se que o avanço da vaga neoliberal iniciada no Reino Unido e Estados Unidos recebe a adesão política dos países de economia dependente, como o Brasil, e, em seu bojo incita a ideia da rigidez do Estado Burocrático e da premência na adoção do Estado Gerencialista e, com ele, a forte orientação sustentada pela racionalidade econômica, pela difusão do Estado provedor e causador de um processo infindo de endividamento. O funcionalismo público foi, e tem sido, alvo prioritário da nova gestão pública disputando posição com a ascensão da participação do setor privado nas ações antes realizadas pelo Estado.

O gerencialismo trouxe consigo a precariedade nas relações de trabalho no setor público. No caso das formas de contratação dos professores da educação básica pelos estados e Distrito Federal, essas vêm sendo conduzidas de modo a aniquilar crescentemente o concurso público e contratar profissionais até mesmo sem formação para ministrar aulas às crianças e jovens em todo o país.

\footnotetext{
${ }^{14}$ A Fundação SEADE realiza o cálculo com base no Índice de Vulnerabilidade Social equivalente a 4, 5 ou 6.
} 
Pelos dados analisados é possível prever que a seleção pública para ingresso no magistério pode ter seus dias contados. A redução do número de salas em funcionamento, mesmo que com superlotação de estudantes, o estabelecimento de metas anuais para firmar contratos temporários junto aos docentes, levando-os a vilipendiar sua profissão e a si mesmos, pois para sobreviverem devem assumir um papel improvisado diante das classes. É assim que a educação no país, e mais especificamente a adotada no estado de São Paulo, concebe o ato de educar a população e desvaloriza os profissionais da educação.

A análise em três instâncias: Brasil, estado de São Paulo e Região Metropolitana de Campinas, revela a existência de um padrão para a precariedade entre professores. Há algumas oscilações entre estados e mesmo municípios na RMC, mas todos os percentuais gravitam em busca de um mesmo objetivo que, mais recentemente, se sofistica. Para além dos contratos temporários, a Secretaria da Educação de São Paulo passou a limitálos e se avoluma a quantidade de aulas não atribuídas nas diretorias regionais. As entrevistas realizadas em outros estudos, por nós conduzidos, apontam que as crianças estão ficando efetivamente sem aula.

A articulação dos índices de precariedade somados aos de vulnerabilidade social apontam que as localidades mais pobres contam com menor quantidade de professores concursados e predominam na "cordilheira da pobreza" (VENCO, 2021). Apreende-se, portanto, que o discurso da qualidade da educação não passa, meramente, de discurso político e que, efetivamente, não há valorização dos profissionais da educação. 
BARBOSA, Andreza; JACOMINI, Márcia; FERNANDES, Maria José; VENCO, Selma. Contratação, carreira, vencimento e jornada dos profissionais da educação estadual paulista (1995-2018). Educação \& Sociedade, Campinas, 2021. No prelo.

BEAUD, Stéphane; PIALOUX, Michel. Retour sur la condition ouvrière. Paris: Fayard, 1999.

BRASIL. Lei $\mathbf{n}^{\circ} \mathbf{8 . 7 4 5}$, de 9 de dezembro de 1993. Dispõe sobre a contratação por tempo determinado para atender a necessidade temporária de excepcional interesse público, nos termos do inciso IX do art. 37 da Constituição Federal, e dá outras providências. Brasília: Presidência da República, 1993.

BRASIL, Decreto n 2.271, de 7 de julho de 1997, dispõe sobre a contratação de serviços pela Administração Pública Federal direta, autárquica e fundacional e dá outras providências. Brasília: Presidência da República, 1997.

BRASIL, [Constituição (1934)]. Constituição da República Federativa dos Estados Unidos do Brasil, promulgada em 16 de julho de 1934. Brasília: Presidência da República, 1934. Disponível em: http://www.planalto.gov.br/ccivil_03/constituicao/constituicao34.htm. Acesso em: 11 ago. 2020.

BRASIL, [Constituição (1988)]. Constituição da República Federativa do Brasil de 1988. Brasília: DF, Presidência da República, 1988. Disponível em http://www.planalto.gov.br/ccivil_03/constituicao/constituicao.htm. Acesso em: 11 ago. 2020.

BRASIL. Receita Federal. Arrecadação UF 2019. Brasília: Presidência da República, 2019. Disponível em

https://receita.economia.gov.br/dados/receitadata/arrecadacao/arrecadacao-porestado/arrecadacao-uf-2019. Acesso em: 01 jul. 2020.

BRESSER-PEREIRA, Luiz Carlos. Reforma do Estado para a cidadania: a reforma gerencial brasileira na perspectiva internacional. São Paulo: Editora 34, 1998.

CASTEL, Robert. As metamorfoses da questão social: uma crônica do salário. Petrópolis: Vozes, 1998.

CINGOLANI, Patrick. La précarité. Paris: PUF, 2005.

CINGOLANI, Patrick. Precarité. In: BERVORT, A. et al. Dictionnaire du travail. Paris: PUF, 2012.

DEDECCA, Claudio Salvadori. Notas sobre a evolução do mercado de trabalho no Brasil. Brasil. J. Polit. Econ., São Paulo, v. 25, n. 1, p. 113-130, mar. 2005. Disponível em: http://www.scielo.br/scielo.php?script=sci_arttext\&pid=S0101-

31572005000100006\&lng=en\&nrm=iso. Acesso em: 02 ago.

2020. https://doi.org/10.1590/0101-35172005-1640 .

DELGADO, Maurício. Godinho. Curso de Direito do Trabalho. São Paulo: LTR, 2007. 
DI PIETRO, Maria Sylvia. Zanella. Direito administrativo. Rio de Janeiro: Forense, 2016.

FUNDAÇÃO SEADE. Pesquisa perfil municipal. São Paulo: SEADE, [2010]. Disponível em: https://perfil.seade.gov.br/. Acesso em: 11 ago. 2020.

GOLLAC, Michel; VOLKOFF, Serge. Les conditions de travail. Paris: La Découverte, 2007.

INSTITUTO NACIONAL DE ESTUDOS E PESQUISAS EDUCACIONAIS ANÍSIO TEIXEIRA (INEP). Censo escolar 2011 - 2020. Brasília: MEC, 2018.

LINHART, Robert. L'Établi. Paris: Minuit, 1978.

LINHART, Danièle; MARUANI, Margareth. Précarisation et destabilisation des emplois ouvriers, quelsques hypothèses. Travail et Emploi, [Paris], n. 11, 01, p. 27-36 1982.

LINHART, Danièle. Les conditions paradoxales de la résistance au travail. Nouvelle revue de psychosociologie, [Toulouse], v. 1, n. 7, p. 71-83, 2009.

MAGAUD, Jacques. Vrais et faux salariés. Sociologie du travail, v. 16, n. 1, p. 1-18, jan./mars 1974.

MATTOS, Rosemary. A política educacional no estado de São Paulo (2007-2010) e suas articulações com o trabalho docente. 2012. Dissertação (Mestrado em educação) Universidade Metodista de Piracicaba, Piracicaba, 2012.

MELLO, Celso Bandeira de. Curso de direito administrativo. São Paulo: Malheiros Editores, 2010.

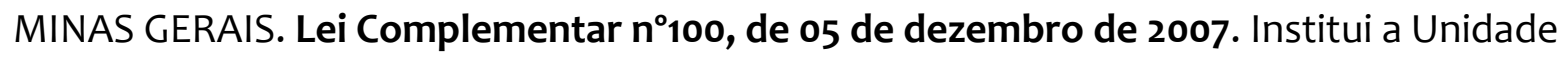
de Gestão Previdenciária Integrada - Ugeprevi - do Regime Próprio de Previdência dos Servidores Públicos do Estado de Minas Gerais e do Regime Próprio de Previdência dos Militares do Estado de Minas Gerais e o Conselho Estadual de Previdência - Ceprev -, altera a Lei Complementar $n^{\circ}$ 64, de 25 de março de 2002, e dá outras providências. Belo Horizonte: Governo do Estado, 2002.

PIALOUX, Michel ; BEAUD, Sthépane. Permanentes e temporários. In: BOURDIEU, Pierre. A miséria do mundo. Petrópolis: Vozes, 2003.

PORS, Anicet; ASCHIERI, Gérard. La fonction publique du XXIème. Ivry-sur-Seine: Les éditions de l'atelier, 2015.

SEDUC-SP. Resolução SE 2, de 8-1-2016. Estabelece diretrizes e critérios para a formação de classes de alunos, nas unidades escolares da rede estadual de ensino. [São Paulo: SEDUC], 2016. Disponível em:

http://siau.edunet.sp.gov.br/ItemLise/arquivos/2_16.HTM?Time=24/02/2017\%2018:06:14. Acesso em: 11 ago. 2020.

SEDUC-SP. Portaria DRHU 12/1999. [São Paulo: SEDUC], 1999. Disponível em: http://www.im prensaoficial.com.br/DO/BuscaDO2001Do cumento_11_4.aspx?link=/1999/executivo\% 2520secao\%2520i/dezembro/15/pag_0011_ 
DQQVA86RKGO4Ke824FoU3RO24RM. pdf\&pagina=11\&data=15/12/1999\&cader no=Executivo\%2ol\&paginaordenacao=10011. Acesso em: 11 ago. 2020.

SEDUC-SP. Decreto N 64.937, de 13 de abril de 2020. Dispõe sobre medidas de redução de despesas com pessoal e encargos sociais, durante a vigência do estado de calamidade pública decorrente da Emergência em Saúde Pública Internacional, no contexto da pandemia da COVID-19 (Novo Coronavírus). [São Paulo: SEDUC], 2020. Disponível em: https://www.al.sp.gov.br/norma/193532. Acesso em: 11 ago. 2020.

SEDUC-SP. Boletim Informativo CGRH. Comunicado 171/2020, São Paulo, ano 05, ed. 1, p. 21, de 22 abr. 2020. Disponível em

<https://midiasstoragesec.blob.core.windows.net/001/2020/04/boletim-informativo-cgrh01-22-04-2020-2.pdf> Acesso em 01. jul. 2021.

VENCO, Selma. Professores da educação básica rumo à uberização ou ao desemprego? Uma análise das relações de trabalho nas escolas estaduais da região metropolitana de Campinas. Revista Horizontes, Itatiba, 2021. No prelo. 